\title{
Ethnobiology 5: Interdisciplinarity in an Era of Rapid Environmental Change
}

\author{
Steve Wolverton
}

Author address: University of North Texas, Department of Geography, Institute of Applied Science, Denton, TX 76203. wolverton@unt.edu

Received: September 24, 2012

Volume: 4:21-25

Published: January 21, 2013

(C) 2013 Society of Ethnobiology

\begin{abstract}
Ethnobiology 5 stems from Eugene Hunn's four phases of the history of ethnobiology and focuses on the relevance of ethnobiological research in the context of environmental and cultural change. It refers to a contemporary phase of the field's historical development. In this paper, I argue that ethnobiology is preadapted to be a scholarly umbrella for a number of disciplines that concern human-environment interactions, suggesting that one goal of Ethnobiology 5 is to bridge traditional academic boundaries in order to broaden the community of ethnobiologists. Another goal of Ethnobiology 5 is to capitalize on and communicate the relevance of ethnobiological scholarship for solving problems related to contemporary environmental and cultural crises. Indeed, ethnobiology is not a subfield of any traditional discipline and by the nature of its name bridges humanities, social science, and science. Ethnobiology has always been interdisciplinary in terms of its subject matter, yet its community of scholars is relatively small compared to mission-driven disciplines, such as conservation biology. Venues for publication and presentation of ethnobiological research, as well as how ethnobiologists portray their research, are critical to growing ethnobiology.
\end{abstract}

Key Words: Ethnobiology 5, conservation biology, interdisciplinarity, biocultural conservation

The term 'ethnobiology' was coined by biologists, has been adopted by anthropologists, spans into archaeobotany and zooarchaeology, and correspondingly provides an umbrella for an astonishing array of subject matter (Ford 2011; references in Anderson et al. 2011). No longer an unadulterated convergence of ethnozoology with ethnobotany (Ford 2011), the short definition of ethnobiology used by the Society of Ethnobiology is "the scientific study of dynamic relationships among peoples, biota, and environments." Under this brief but expansive definition, ethnobiologists do many things along a spectrum from pure to applied research. As is the case for many disciplines during the last two decades, ethnobiologists could go so far as to delineate an applied ethnobiology that focuses on the relevance of ethnobiological data in conservation science, environmental justice, and related areas of scholarship, but to do so could fragment an already small body of scholars. However, to be "applied," the ethnobiologist needs to do nothing more than redirect the relevant nature of 'knowing about humanenvironment relationships' already central to the field toward various disciplines concerned with conservation science and environmental studies. Indeed, ethnobiologists are increasingly addressing environmental management, conservation, environmental ethics, and related topics (e.g., Anderson 2010; Gilmore and Young 2012; Lepofsky 2009; Müller and Dan Guimbo 2010), but this does not represent a discipline-wide collective enterprise. More can be done to engage the relevance of ethnobiological research for addressing problems related to global environmental and cultural crises. To do so requires that ethnobiologists address a broader audience of scholars.

While most ecologists identify themselves as biologists, scholars in the fields of human ecology, ethnoecology, and environmental anthropology do not necessarily see themselves as ethnobiologists. Why is this the case? It relates to the historical effect of ethnobiology being forged on the boundaries of entrenched disciplines; although ethnobiology draws from a diverse crowd, most of its scholars find their primary academic homes in mainstream anthropology and biology, which have deeper histories. Because it was framed and has existed inbetween traditional disciplines, ethnobiology is well-suited to serve as an interdisciplinary umbrella for environmental scientists, conservation biologists, restoration ecologists, 
environmental philosophers, and others who engage in applied research related to human-environment interactions. However, the ability of ethnobiology to include others under this umbrella by broadening its audience has developed slowly. An example illustrates why this is so.

Conservation biology provides an interesting point of contrast to ethnobiology; its subject matter is so deeply and pragmatically relevant that it stands nearly separate from conventional biology and ecology. The mission of conservation biology is powerful because it relates scholarship to preservation and protection of biodiversity (Lindenmeyer and Hunter 2010; Meine et al. 2006). From its relatively narrow moniker, the field has reached outward, branching into ecosystem ecology, population genetics, and biocultural conservation (Figure 1). The mission of conservation biology 'to provide the opportunity of continued evolution of biota' (sensu Frankel and Soule 1981:4) is so persuasive that the field transcends traditional disciplinary boundaries and scales of research.

Audience Ethnobiologists Conservation Biologists

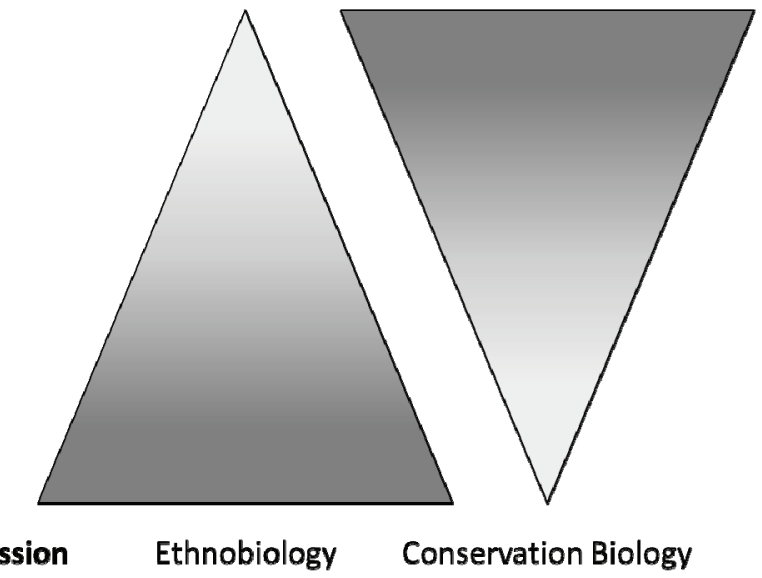

Figure 1. A simple, ordinal scale model of the missions of Ethnobiology and Conservation Biology represented as continua connected to respective audiences. The implication is that the audience of ethnobiologists is small, yet the mission of the field is to study the Earth's various human-environmental interactions in time and space, which is broad. In contrast, conservation biology is mission driven and is explicitly concerned with support of continued evolution of biological systems, from populations and species to communities and ecosystems. Yet, its audience is enormous because its relevance is immediately transparent.
In comparison, ethnobiology represents intriguing subject matter without the unity provided by a narrow and compelling mission. Indeed, there are ethnobiologists who are advocates for social and environmental justice and there are those who are activists supporting preservation and protection of cultural and biological diversity. In contrast to conservation biology, however, there are multiple objectives in ethnobiology that tend to be topical, and there is no focal and uniform mission shared by most ethnobiologists. Nonetheless, biocultural conservation, environmental co-management, environmental ethics, and other topics relevant to addressing and solving modern environmental and cultural problems at local, regional, and global scales, might find a comfortable, explicitly acknowledged, and well-populated home in ethnobiology (Nabhan et al. 2011a, 2011b). Currently, the field is dominated by anthropologists, as well as ethnobotanists, but also attracts a smaller number of geographers, archaeologists, and paleobiologists interested in addressing human environmental relationships. In simplistic terms, conservation biology and ethnobiology are inverted versions of one another, focusing (these days) on similar subject matter but with different objectives and audiences (Figure 1). Indeed, the audience of ethnobiology beyond its own frontiers is quite small relative to that of conservation biology.

An expansive future for ethnobiology lies beyond its traditional disciplinary homes in anthropology and biology, moving toward human geography, environmental philosophy, political ecology, conservation biology, and related fields with more explicit ideological missions. Ethnobiology is, perhaps, pre-adapted to become a scholarly home for interdisciplinary research on human environment relationships because the field is currently populated (in large part, but by no means in total) by anthropologists who are trained to understand and transcend cultural boundaries (sensu Nabhan 2009:6; Nabhan and Martinez 2012:4). Scholarly disciplines are cultural institutions (Ball and Lacey 1980), and an ethnobiology willing to traverse disciplinary and cultural boundaries has the potential to maximize its own relevance (Nabhan et al. 2011a). Momentum toward a focus on application and practical relevance in ethnobiological scholarship represents what Wyndham et al. (2011:124) describe as "Ethnobiology 5," piggy-backing from Hunn's (2007; Ford 2011) four phases of ethnobiology's historical development. Phase 5 requires that ethnobiologists address "the needs of a world coping with 
rapid ecological change and shifting political economies" (Wyndam et al. 2011:124; see also Nabhan et al. 2011b). That said, how can Ethnobiology 5 continue to gain momentum? Modest solutions might include hosting conferences, organizing sessions, and publishing papers that reach across the politically entrenched divides in academia in order to invite new perspectives. These offer particular solutions, but there are two additional goals that should be adopted as core objectives.

First, to engage the broader audience of environmental studies, media, philosophy, and science, ethnobiologists should continue to publish in flagship ethnobiology journals and increase the frequency of papers that explicitly address Phase 5 (e.g., Beserra de Farias et al. 2010; Gilmore and Young 2012). For example, it is one matter to publish a plant taxonomy and to debate the cognitive reality of language and classification, it is quite another to link diversity in plant taxonomy to diversity in language (Maffi 2001; Stepp et al. 2005). And it is still yet another to explicitly recognize that extinction rates in biology and culture (including language) can share a biocultural geographic pattern (sensu Albuquerque and Muniz de Medieros 2012; e.g., Maffi 2001; Stepp et al. 2004, 2005). Ethnobiologists are "on the ground" in such biocultural geographic contexts and command the intimate details concerning human-environmental relationships situated within subtle ecologies of time and place (Wyndham 2009), and it is just these subtle ecologies that are of growing interest in community based conservation and environmental comanagement. An equally pervasive argument can be made that ethnobiologists should publish their research in ecology, environmental science, and conservation journals, but then the work may lose its ethnobiological identity. Common use of the terms ethnobiology, ethnobiological research, and ethnobiologist in conservation, ecology, and related journals will broaden the exposure of our research and may direct scholars to the Society of Ethnobiology and its flagship journals as homes for interdisciplinary research on human-environment interactions.

Though it has been argued that ethnobiologists have much to offer in terms of cultural theory (Nabhan et al. 2011a:3), a clear strength of the discipline related to Phase 5 is the vast empirical record of humans in places and time-that is, we have data. The cultural, geographic, and evolutionary scope of ethnobiological subject matter, when conveyed broadly, represents what environmental philosopher Albert Borgmann (2000:103) terms "disclosure." A disclosive perspective is one that shifts the human experiential scale; for example, a human lifespan is miniscule in terms of geological time. Moreover, environmental impacts when recognized in terms of the contingency of Earth are more disclosive of the magnitude of particular effects, such as extinction (Wolverton and Lyman 2012). The same can be said for cultural diversity in environmental knowledge (Wolverton et al. 2011); cross-cultural awareness of diverse and local environmental values transcends any particular policy or aim of environmental management and discloses new information relevant to local communities and economies (Anderson 2010; Müller and Dan Guimbo 2010). It is the empirical nature of subtle ecologies in varied contexts that provides this disclosure. A focus on the disclosive aspects of ethnobiological scholarship should be developed, as most if not all ethnobiological research is simply relevant to biocultural conservation, environmental ethics and justice, and environmental management (Lepofsky 2009).

Second, the Ethnobiology Conference is an important venue for generating and encouraging the conversation about the relevance of ethnobiology in a changing world. In recent years, the conference has been organized around important themes, such as "The Meeting Place: Integrating Ethnobiological Knowledge" (2010), "Conservation and Communities" (2012), and "Climate Change and Ethnobiology" (2013). Such themes enable ethnobiologists to accomplish two important goals: first, it encourages established ethnobiologists to bring the relevance of their research to the forefront of ongoing scholarship within ethnobiology. Second, and equally important is it allows the audience to grow because themes conveying messages relevant to the modern global environmental and cultural crises are concerns addressed in multiple areas of scholarship. It is important that conservation biologists, environmental philosophers, eco-critical writers, and environmental scientists be invited to the forums provided by the Ethnobiology Conference. Encouraging their attendance at the Society of Ethnobiology's conferences will require new conceptual spaces within which they can situate their own scholarship. The conference should continue to provide an umbrella for such conversations, and doing so will change the community of scholars from one situated primarily in anthropology and botany to one that is even more interdisciplinary than it is currently. 
Ethnobiology has a history of being inherently fascinating to ethnobiologists. Scholars of ethnobiology, however, are also deeply concerned about modern environmental and cultural crises ranging from overharvest of marine fish populations to loss of native heirloom plant varieties, to the richness of human cognition and language, to the deep temporal evolutionary implications of biological and cultural extinction. This is our own subtle ecology, something that sometimes is hidden in our plant taxonomies, our tables of data on faunal remains from archaeological sites, our language maps, and our ethnographies. Our data are relevant and essential to solving large scale environmental and cultural problems because, as stated by Rozzi (1999), problems of humanenvironmental impact cannot be solved unless the values of people in contemporary societies change, and values do not change unless experiences change. The clearest path to initiating such progress is through direct encounter with plants, animals, environments, the outdoors, Earth-if ethnobiology is nothing else, it comprises a record of such encounters from many times and places.

\section{Acknowledgements}

I wish to thank Dana Lepofsky for thoughtful review comments and James R. Welch and Cynthia Fowler for comments and support to publish this paper in EBL.

\section{Declarations}

Permissions: Not applicable.

Sources of funding: None declared.

Conflicts of interest. None declared.

\section{References Cited}

Albuquerque, U. P. and P. M. Medeiros. 2012. Systematic Reviews and Meta-Analysis Applied to Ethnobiological Research. Ethnobiology and Conservation 1:6.

Anderson, E. N. 2010. The Pursuit of Ecotopia: Lessons from Indigenous and Traditional Societies for the Human Ecology of Our Modern World. Praeger Press, Santa Barbara, CA.

Anderson, E. N. 2011. Ethnobiology: Overview of a Growing Field. In Ethnobiology, edited by E. N. Anderson, D. M. Pearsall, E. S. Hunn, and N. J. Turner, pp. 1-14. Wiley-Blackwell, Hoboken, NJ.
Anderson, E. N., D. M. Pearsall, E. S. Hunn, and N. J. Turner, eds. 2011. Ethnobiology. Wiley-Blackwell, Hoboken, NJ.

Ball, S. J. and C. Lacey. 1980. Subject Disciplines as the Opportunity for Group Action: A Measured Critique of Subject Sub-cultures. In Teacher Strategies: Explorations in the Sociology of the School, edited by P. Wood, pp. 149-177. Routledge, New York.

Baserra de Farias, G., A. G. C. Alves, and J. Geraldo. 2010. Mythological Relations between the "Lavandeira" Birds Fluvicola nengeta and Motacilla alba in Northeast Brazil and Northwest Spain: Possible Cultural Implications for Conservation. Journal of Ethnobiology 30:240-251.

Borgmann, A. 2000. The Transparency and Contingency of the Earth. In Earth Matters: The Earth Sciences, Philosophy, and the Claims of Community, edited by R. Frodeman, pp. 99-106. Prentice Hall, Upper Saddle River, NJ.

Ford, R. I. 2011. History of Ethnobiology. In Ethnobiology, edited by E. N. Anderson, D. M. Pearsall, E. S. Hunn, and N. J. Turner, pp. 15-26. Wiley-Blackwell, Hoboken, NJ.

Frankel, O. H., and M. E. Soulé. 1981. Conservation and Evolution. Cambridge University Press, Cambridge, UK.

Gilmore, M. P. and J. C. Young. 2012. The Use of Participatory Mapping in Ethnobiological Research, Biocultural Conservation, and Community Empowerment: A Case Study from the Peruvian Amazon. Journal of Ethnobiology 32:6-29.

Hunn, E. 2007. Ethnobiology in Four Phases. Journal of Ethnobiology 27:1-10.

Lepofsky, D. 2009. The Past, Present, and Future of Traditional Resource and Environmental Management. Journal of Ethnobiology 29:161-166.

Lindenmayer, D., and M. Hunter. 2010. Some Guiding Concepts for Conservation Biology. Conservation Biology 24:1459-1468.

Maffi, L. 2001. Introduction: On the Interdependence of Biological and Cultural Diversity. In On Biocultural Diversity: Linking Language, Knowledge, and the Environment, edited by L. Maffi, pp. 1-50. Smithsonian Institution Press, Washington, DC.

Meine, C., M. Soulé, and R. F. Noss. 2006. A Mission- 
Driven Discipline": the Growth of Conservation Biology. Conservation Biology 20:631-651.

Müller, J., and I. Dan Guimbo. 2010. Letting Wood Rot: A Case Study on Local Perceptions of Global Conservation Initiatives (Boumba, Niger). Ethnobiology Letters 1:40-50.

Nabhan, G. P. 2009. Perspectives in Ethnobiology: Bridging Disciplines, Cultures and Species. Journal of Ethnobiology 29:3-7.

Nabhan, G. P., K. Chambers, D. Tecklin, E. Perramond, and T. E. Sheridan. 2011a. Ethnobiology for a Diverse World - Defining New Disciplinary Trajectories: Mixing Political Ecology with Ethnobiology. Journal of Ethnobiology 31:1-3.

Nabhan, G. P., F. Wyndham, and D. Lepofsky. 2011b. Ethnobiology for a Diverse World: Ethnobiology Emerging from a Time of Crisis. Journal of Ethnobiology 31:172-175.

Nabhan, G. P. and D. Martinez. 2012. Ethnobiology for a Diverse World - Traditional Ecological Knowledge and Endangered Species Recovery: Is Ethnobiology for the Birds? Journal of Ethnobiology 32:1-5.

Rozzi, R. 1999. The Reciprocal Links between Evolutionary-Ecological Sciences and Environmental Ethics. Bioscience 49:911-921.

Stepp, J. R., S. Cervone, H. Castaneda, A. Lasseter, G. Stocks, and Y. Gichon. 2004. Development of a GIS for Global Biocultural Diversity. Policy Matters

\section{3:267-271.}

Stepp, J. R., H. Castaneda, and S. Cervone. 2005. Mountains and Biocultural Diversity. Mountain Research and Development 25:223-227.

Wolverton, S., C. R. Randklev, and A. Barker. 2011. Ethnobiology as a Bridge between Science and Ethics: An Applied Paleozoological Perspective. In Ethnobiology, edited by E. N. Anderson, D. M.

Pearsall, E. S. Hunn, and N. J. Turner, pp. 115-132. Wiley-Blackwell, Hoboken, NJ.

Wolverton, S. and R. L. Lyman. 2012. Introduction to Applied Zooarchaeology. In Conservation Biology and Applied Zooarchaeology, edited by S. Wolverton and R. L. Lyman, pp. 1-22. University of Arizona Press, Tucson.

Wyndham, F. S. 2009. Spheres of Relations, Lines of Interaction: Subtle Ecologies of the Rarámuri Landscape in Northern Mexico. Journal of Ethnobiology 29:271-295.

Wyndham, F. S., D. Lepofsky, and S. Tiffany. 2011.

Taking Stock in Ethnobiology: Where Do We Come From? What Are We? Where Are We Going? Journal of Ethnobiology 31:110-127.

\section{Biosketch}

Steve Wolverton is an archaeologist and ecologist in the Department of Geography at the University of North Texas. He is one of the founding editors of Ethnobiology Letters, and his research focuses on the intersections between zooarchaeology, ethnobiology, and conservation biology. 